\title{
Positional variation and localization of the mental foramen
}

\section{Abstract}

Objectives: The anatomical position of the mental foramen (MF) is variable and the knowledge of its exact location is clinically relevant.

Method: Fifty two mental foramina in twenty six dry mandibles were analyzed to ascertain the shape, size, direction, presence of accessory foramina, position in relation to anatomical landmarks in an adult Sri Lankan population.

Results: The MF was predominantly oval in shape $(96.1 \%$ and $92.3 \%$ on the right and left side, respectively) and situated on the longitudinal axis of the mandibular $2 \mathrm{nd}$ premolar tooth $(63.6 \%$ and $45.4 \%$ on the right and left side, respectively). The mental foramina were located at a mean distance of $13.34 \pm 1.79 \mathrm{~mm}$ and $12.89 \pm 1.56 \mathrm{~mm}$, vertically above the lower border of the mandible on the right and left side, respectively, and $13.23 \pm 2.69 \mathrm{~mm}$ and $13.47 \pm 3.06 \mathrm{~mm}$ vertically below the alveolar margin on the right and left side, respectively. The mean distance from the MF to the mandibular midline was $25.65 \pm 1.75$ and $25.5 \pm 1.57$ on the right and left side, respectively; the mean distance from the MF to the posterior border of the ramus of mandible was $65.01 \pm 5.05$ and $64.58 \pm 4.38$ on the right and left side, respectively.

Conclusion: The observations made in this study will be useful for surgeons to localize the mental neurovasculature when planning the mental nerve block or surgery around the mental foramen.

Keywords: mental foramen, morphology, position, variations, localization
Volume 5 Issue I - 2018

\author{
Deepthi Nanayakkara,' Harshana Sampath,' \\ Ruwanthi Manawaratne,' Roshan Peiris,' \\ Amal Vadysinghe, ${ }^{2}$ Kapila Arambawatte, 1 \\ Jayampathi Disanayake ${ }^{3}$ \\ 'Department of Basic Sciences, University of Peradeniya, Sri \\ Lanka \\ ${ }^{2}$ Department of Forensic Medicine, University of Peradeniya, \\ Sri Lanka \\ ${ }^{3}$ Department of Anatomy, University of Peradeniya, Sri Lanka
}

Correspondence: Deepthi Nanayakkara, Division of Anatomy, Department of Basic Sciences, Faculty of Dental Sciences, University of Peradeniya, Sri Lanka, Tel +948I2222035, Email deepthinanayakkara@yahoo.com

Received: September 25, 2017 | Published: February 07, 2018
Abbreviations: MF, mental foramen; VD, vertical diameter; $\mathrm{HD}$, horizontal diameter

\section{Introduction}

The mental foramen (MF) is a small opening located on the anterolateral aspect of the body of the mandible. It represents the exit point of the mandibular canal through which the mental neurovascular bundle emerges. ${ }^{1}$ The mental nerve is the terminal branch of the inferior alveolar nerve. The nerve is accompanied by the mental artery, a branch of the inferior alveolar artery. The mental nerves and vessels provide sensory innervation and blood supply to the chin, skin and mucous membrane of the lower lip, and labial gum from the midline to as far posterior as the second premolar tooth. ${ }^{2}$

The mental foramina are commonly encountered when administering regional anaesthesia for the mental nerve block, in osteotomies required for various maxillofacial and orthognathic surgeries, and in placement of dental implants. As the mental neurovascular bundle is susceptible to injury during these procedures, it is important to be able to reliably and accurately predict its position to avoid iatrogenic injury to the structures that traverse these foramina.

Standard texts of anatomy describe the MF to be located in the body of the mandible, midway between the upper and lower borders. Further, it is stated to lie between the apices of the first and second premolar teeth. ${ }^{2}$ However, the MF has been reported to vary in its position $^{3-5}$ and shape $e^{6,7}$ in different ethnic groups. Numerous studies have documented the most common position of the MF to be between the first and second premolars. In studies done in the North American whites, ${ }^{8}$ Bangladeshis ${ }^{9}$ and Israelis, ${ }^{7}$ the MF was located most commonly between the first and second premolars. On the other hand, studies conducted in Malawian, ${ }^{10}$ Peruvian, ${ }^{11}$ North Indian, ${ }^{12}$ Kenyan African ${ }^{13}$ and Saudi ${ }^{14}$ populations have demonstrated that the MF was most commonly positioned in line with the second premolar tooth. Hence, population specific studies describing the precise anatomical position and possible variations, and methods of accurately localizing the MF are important to ensure safe and successful regional anaesthesia and surgical procedures.

Even though variations of the MF are often encountered in different population groups, ranging from differences in its position on the anterolateral surface of the body of the mandible ${ }^{4}$ to the presence of accessory foramina ${ }^{15}$ or even complete absence of the foramen in occasional cases ${ }^{16}$ studies available with regard to the morphology and position of the MF in the Sri Lankan population are scanty. Therefore, the present study was undertaken to determine the shape, direction, presence of accessory foramina, dimensions of the MF, and its position in relation to clinically relevant anatomical landmarks.

\section{Materials and methods}

Fifty two mental foramina from twenty six adult dry mandibles formed the study material. The mandibles were collected from the Division of Anatomy, Faculty of Dental Sciences, and Department of Anatomy, Faculty of Medicine, University of Peradeniya, Sri Lanka. Approval from the institutional ethical committee was obtained before pursuing the study (number FDS-FRC/2014/06). The mandibles with no apparent gross pathology, deformity or traumatic lesions were included in the study. The mandibles that showed alveolar bone resorption and those less than 18years of age were excluded. 
The mental foramina were visually assessed and the shape, presence of accessory foramina, and the direction were recorded. The shape was described as displaying an oval, triangular or a circular outline. The direction of the opening of the MF through the anterolateral surface of the mandible was determined by inserting a flexible wire and recorded as posterior, posterosuperior or anteroinferior.

The position of MF in relation to the teeth of the mandible was classified according to the method described in a previous study ${ }^{12}$ (Figure 1). Six positions (positions I-VI) are described as follows:

I. The MF situated on the longitudinal axis passing between the canine and the first premolar.

II. The MF situated on the longitudinal axis passing through the first premolar.

III. The MF situated on the longitudinal axis passing between the first and second premolars.

IV. The MF situated on the longitudinal axis passing through the second premolar.

V. The MF situated on the longitudinal axis passing between the second premolar and the first molar.

VI. The MF situated on the longitudinal axis passing through the first molar.

To analyze the size, and the relative position of the MF, the following parameters on the right and left sides were measured using a digital vernier caliper to the nearest $0.01 \mathrm{~mm}$ (Mitutoyo, Japan).

i. The maximum vertical diameter (VD).

ii. The maximum horizontal diameter (HD).

iii. The vertical distance from the alveolar margin to the MF.

iv. The vertical distance from the base of the mandible to the MF.

v. The distance from the mandibular midline to the MF.

vi. The distance from the posterior border of the mandible to the MF

Table I Shape of the mental foramen on the right and left sides of the mandibles

\begin{tabular}{lll}
\hline Shape of mental foramen & Right & Left \\
\hline Round & 3.9 & 7.7 \\
Oval & 96.1 & 92.3 \\
\hline
\end{tabular}

Table 2 Position of the mental foramen in relation to lower teeth

\begin{tabular}{lllllll}
\hline Position & I & II & III & IV & V & VI \\
\hline Right & 0 & 0 & 22.8 & 63.6 & 13.6 & 0 \\
Left & 0 & 0 & 18.2 & 45.4 & 36.4 & 0
\end{tabular}

I. The MF lying on the longitudinal axis passing between the canine and the first premolar

II. The MF lying on the longitudinal axis passing through the first premolar

III. The MF lying on the longitudinal axis passing between the first and second premolars

IV. The MF lying on the longitudinal axis passing through the second premolar

V. The MF lying on the longitudinal axis passing between the second premolar and the first molar

VI. The MF lying on the longitudinal axis passing through the first molar 
The position of the MF in relation to the mandibular teeth is shown in Table 2. The foramen was most commonly positioned in the longitudinal axis passing through the second premolar on both the right $(63.6 \%)$ and left $(45.4 \%)$ sides, followed by position III on the right side $(22.8 \%)$ and position $\mathrm{V}$ on the left side $(36.4 \%)$ (Table 2$)$. Foramina located in positions I, II and VI were not seen in any of the mandibles examined in this study.
The mean vertical and horizontal diameters of MF and linear distances from the MF to selected surgically important anatomical landmarks, the mandibular midline, posterior border of the ramus of the mandible, alveolar margin and lower border of the mandible on the right and left sides, are shown in Table 3.

Table 3 Measurements of the mental foramina on the left and right sides of the mandibles

\begin{tabular}{|c|c|c|c|c|c|c|c|}
\hline \multirow{2}{*}{ Measurement } & \multicolumn{3}{|l|}{ Right } & \multicolumn{3}{|l|}{ Left } & \multirow{2}{*}{ P value } \\
\hline & Minimum & Maximum & $\operatorname{Mean} \pm$ SD & Minimum & Maximum & Mean \pm SD & \\
\hline Vertical diameter & 1.72 & 3.45 & $2.38 \pm 0.41$ & 1.72 & 3.45 & $2.41 \pm 0.46$ & NS \\
\hline Transverse diameter & 2.26 & 5.04 & $3.19 \pm 0.72$ & 2.04 & 4.31 & $3.10 \pm 0.65$ & NS \\
\hline $\begin{array}{l}\text { Distance from MF to mandibular } \\
\text { midline }\end{array}$ & 22.57 & 29.21 & $25.65 \pm 1.75$ & 21.42 & 28.21 & $25.5 \pm 1.57$ & NS \\
\hline $\begin{array}{l}\text { Distance from MF to posterior } \\
\text { border of ramus }\end{array}$ & 55.72 & 74.15 & $65.01 \pm 5.05$ & 55.3 & 74.53 & $64.58 \pm 4.38$ & NS \\
\hline $\begin{array}{l}\text { Distance from MF to alveolar } \\
\text { margin }\end{array}$ & 6.42 & 18.49 & $13.23 \pm 2.69$ & 7.7 & 18.32 & $13.47 \pm 3.06$ & NS \\
\hline $\begin{array}{l}\text { Distance from MF to lower border } \\
\text { of mandible }\end{array}$ & 10.13 & 16.52 & $13.34 \pm 1.79$ & 10.66 & 15.95 & $12.89 \pm 1.56$ & NS \\
\hline
\end{tabular}

NS, not significant

\section{Discussion}

The mental nerve which emerges through the MF onto the lateral surface of the mandible is responsible for the sensory innervation of the ipsilateral mucosa around the premolar region, skin of the chin as well as the skin and mucosa of the lower lip. ${ }^{1}$ As the mental nerve provides a considerably large area of sensory innervation, it is a nerve of choice for a regional nerve block. The determination of the accurate anatomical position of the mental neurovascular bundle is essential during surgery because injury to the mental nerve may result in untoward outcomes such as bleeding, hypoesthesia or paraesthesia in the region innervated by this neurovascular bundle.

The MF was present bilaterally in all mandibles examined. This is in accordance with the previous studies. ${ }^{17}$ Although the presence of a single foramen was the most common $(88.5 \%)$, accessory foramina were found in $11.5 \%$ of mandibles. The occurrence of accessory mental foramina is well documented in the literature. ${ }^{15,17} \mathrm{~A}$ wide variation in the occurrence of accessory mental foramina among different populations is also documented. Sawyer et al. ${ }^{15}$ investigated the accessory mental foramina in four different population groups, and reported an incidence of $1.4 \%, 1.5 \%, 5.7 \%$ and $9.0 \%$, in American Whites, Asian Indians, African Americans and Pre-Columbian Nazca Indians, respectively. The presence of accessory foramina is important for surgeons because there may be an accessory branch of the mental nerve passing through it. The surgeon would be forewarned to investigate in the patient to detect the presence of accessory foramina with neurovascular bundles before dissecting the mental foramen region.

It is interesting to note that the absence of mental foramina has also been documented in the literature. In a study by Defreitas et al. ${ }^{16}$ on 1,435 mandibles $(2,870$ sides $)$ the foramen was absent in three cases, twice in the right side $(0.06 \%)$ and once in the left side $(0.03 \%)$. More recently unilateral ${ }^{18}$ and bilateral absence ${ }^{19}$ of the MF have been detected in patients undergoing CBCT.
In the present study, the predominant shape of the MF was oval on both right (96.1\%) and left (92.3\%) sides. An incidence of $92.0 \%$ and $65.5 \%$ of oval foramina has been observed in Indian ${ }^{20}$ and Israeli ${ }^{7}$ populations, respectively (Table 4). On the other hand, Singh \& Srivastava ${ }^{17}$ reported the shape was predominantly round with $94 \%$ and $87 \%$ on the right and left side, respectively.

The mean VD of MF in our study was $2.38 \pm 0.41 \mathrm{~mm}$ and $2.41 \pm 0.46 \mathrm{~mm}$ on the right and left side, respectively and the mean HD was $3.19 \pm 0.72 \mathrm{~mm}$ and $3.10 \pm 0.65 \mathrm{~mm}$ on the right and left side, respectively. The values seem very close to those of Oguz \& Boskir $^{21}$ and Ilayperuma ${ }^{22}$ for both HD and VD. In a study in north Indians $^{12}$ the mean VD was $2.61 \pm 0.17 \mathrm{~mm}$ and $2.53 \pm 0.14 \mathrm{~mm}$ on the right and left side, respectively, while the mean HD was $5.19 \pm 0.24 \mathrm{~mm}$ and $5.12 \pm 0.28 \mathrm{~mm}$ on the right and left side, respectively.

According to some standard texts in anatomy and preceding studies, the MF is most commonly located between the apices of the first and second lower premolar. ${ }^{2,7,8}$ However, this ignores a mass of evidence of varying foraminal positions reported in other populations. ${ }^{10-15}$ Moreover, numerous studies have indicated that the MF shows population and ethnic variations. ${ }^{4}$ According to a study by Santini \& Alayan ${ }^{4}$ on three different population groups, the modal position of the foramen in the Chinese was in line with the long axis of the mandibular second premolar, while in the European and Indian populations it lay between the mandibular first and second premolar. Further, in a study by Cutright et al $^{23}$ the MF was reported to be positioned between the mandibular first and second premolars in the Whites and posterior to the mandibular second premolar in the Blacks.

Interestingly, in the present study the MF was located most commonly in the position IV on both right and left sides. This was followed by position III and position $\mathrm{V}$ on the right and left side, respectively. It is also interesting to note that none of the mandibles displayed the MF in positions I, II and VI in this study. This finding is in accordance with a previous study by Amorim et al. ${ }^{24}$ in a 
Brazilian population. Al Jasser \& Nwoku ${ }^{14}$ analyzing 397 panoramic radiographs of the Saudi population reported the MF to be positioned anywhere between the long axis of the canine (position I) to that of the mesiobuccal root of the first molar (position VI).

In studies done on Brazilian, ${ }^{24}$ central Indian, ${ }^{19}$ north Indian ${ }^{12}$ and Turkish populations, ${ }^{5}$ the most common position of the MF was position IV followed by position III (Table 5). In the mandibles of Malawians ${ }^{10}$ and Zimbabweans, ${ }^{6}$ position IV was the most common followed by position V. On the other hand, in the British ${ }^{5}$ and Chinese ${ }^{25}$ populations, the most common position was position III followed by position IV.

Table $4 \mathrm{~A}$ comparison of the shape of mental foramen of the present study and with those reported in previous studies

\begin{tabular}{ll}
\hline & Oval \\
\hline Agarwal \& Gupta, ${ }^{19}$ South Gujarat, India & 92 \\
Gerhenson et al. ${ }^{7}$ Israel & 65.5 \\
Igbigbi \& Lebon, ${ }^{10}$ Malawi & 74.3 \\
Budhiraja et al., ${ }^{12}$ North India & 74.3 \\
Mbajiorgu et al.. ${ }^{6}$ Zimbabwe & 56.3 \\
Present study & 96.1 right side \\
& 92.3 left side
\end{tabular}

Table 5 A comparison of the position of mental foramen of the present study with different populations reported in previous studies

\begin{tabular}{|c|c|c|c|c|c|c|c|c|}
\hline \multirow{2}{*}{ Authors } & \multirow{2}{*}{ Population } & \multirow{2}{*}{ Side } & \multicolumn{6}{|c|}{ Position } \\
\hline & & & I & II & III & IV & $\mathbf{V}$ & VI \\
\hline \multirow{2}{*}{ Amorim et al. ${ }^{24}$} & \multirow{2}{*}{ Brazilian } & Right & 0 & 0 & 19.8 & 71.4 & 8.8 & 0 \\
\hline & & Left & 0 & 0 & 23.1 & 68.1 & 8.8 & 0 \\
\hline \multirow{2}{*}{ Agarwal \& Gupta ${ }^{19}$} & \multirow{2}{*}{ Central Indian } & Right & 0 & 0 & 7.8 & 81.5 & 2.7 & 0 \\
\hline & & Left & 0 & 0 & 7.6 & 81.5 & 3.1 & 0 \\
\hline \multirow{2}{*}{ Budhiraja et al. ${ }^{12}$} & \multirow{2}{*}{ North Indian } & Right & 0 & 3.8 & 20 & 61 & 14.3 & 0 \\
\hline & & Left & 0 & 2.9 & 20.9 & 59.1 & 15.2 & 0 \\
\hline \multirow{2}{*}{ Yesilyurt et al..$^{5}$} & \multirow{2}{*}{ Turkish } & Right & 0 & 5.7 & 34.3 & 55.7 & 4.3 & 0 \\
\hline & & Left & 0 & 7.1 & 25.7 & 61.4 & 5.7 & 0 \\
\hline \multirow{2}{*}{ Present study } & \multirow{2}{*}{ Sri Lankan } & Right & 0 & 0 & 22.8 & 63.6 & 13.6 & 0 \\
\hline & & Left & 0 & 0 & 18.2 & 45.4 & 36.4 & 0 \\
\hline
\end{tabular}

I. The MF lying on the longitudinal axis passing between the canine and the first premolar

II. The MF lying on the longitudinal axis passing through the first premolar

III. The MF lying on the longitudinal axis passing between the first and second premolars

IV. The MF lying on the longitudinal axis passing through the second premolar

V. The MF lying on the longitudinal axis passing between the second premolar and the first molar

VI. The MF lying on the longitudinal axis passing through the first molar 
In the past, attempts have been made to identify satisfactory references to localize the MF. The mandibular midline is one of the most commonly used reference points. The mean distance from the MF to the mandibular midline in the present study was $25.65 \pm 1.75 \mathrm{~mm}$ and $25.5 \pm 1.57 \mathrm{~mm}$ on the right and left side, respectively. There was no significant side difference. The mean distance from the MF to the posterior border of the ramus in the present study was $65.01 \pm 5.05 \mathrm{~mm}$ and $64.58 \pm 4.38 \mathrm{~mm}$ on the right and left side, respectively. The values established for the distances between the MF and mandibular midline and MF and posterior border ramus are lower than those established for Thai and Brazilian population. However, they were relatively similar to those established for a North Indian population. ${ }^{12}$

The position of the MF is usually variable and difficult to locate. It cannot be visualized or palpated clinically. ${ }^{26,27}$ When radiological assessment methods are unavailable, in clinical situations it can be localized in relation to the lower teeth. However, in patients who are edentulous or in those having missing or malpositioned teeth it may be difficult to localize the MF in its modal position. Moreover, the position of MF in relation to lower teeth demonstrates inter-population variations. ${ }^{3-5}$ Hence, in such situations the distances from clinically palpable landmarks such as the mandibular midline, inferior border of the mandible, posterior border of the ramus which are specific for the populations concerned become important in accurately localizing the mental foramen.

\section{Conclusion}

This study reports significant information on the possible variations of morphological characteristics and the position of mental nerve exits in a Sri Lankan population. The mental nerve is the nerve of choice for regional nerve block when performing surgeries in the region of the mandible. The ability to accurately localize the MF is crucial while administering the mental nerve block, and when performing surgery in the region of the MF to avoid injury to the mental nerve. The present study established the distances from the mandibular midline, inferior border of the mandible, posterior border of the ramus to accurately localize the MF. Furthermore, the presence of accessory foramina has a clinical significance, as injury to the branches of the mental nerve that exit through these foramina may cause a sensory deficit. This knowledge is therefore vitally important to the surgeon who is made aware of these variations, and the need to investigate and find out the exact position of the MF before venturing into surgery in this region.

\section{Acknowledgements}

The authors wish to thank Mr. Manjula Dissanayake, Division of Anatomy, and Mr. Vinod Viduranga, Audiovisual Technical Officer, Faculty of Dental Sciences, University of Peradeniya, for the technical support provided.

\section{Conflict of interest}

The authors declare that there is no conflict of interests.

\section{References}

1. Standring S. Gray's Anatomy: The anatomical basis of clinical practice. 40th ed. London: Churchill Livingstone, Elsevier; 2008. p. 1191-1196.

2. Sinnatamby CS. Last's Anatomy-Regional and Applied. 12th ed. London: Churchill Livingstone, Elsevier; 2011.

3. Santini A, Land M. A Comparison of the position of the mental foramen in Chinese and British mandibles. Acta Anat. 1990;137(3):208-212.
4. Santini A, Alayan I. A comparative anthropometric study of the position of the mental foramen in three populations. $\mathrm{Br}$ Dental $\mathrm{J}$. 2012;212(4):188-189.

5. Yesilyurt H, Aydinlioglu A, Kavakli A, et al. Local differences in the position of the mental foramen. Folia Morphol. 2008;67(1):32-35.

6. Mbajiorgu EF, Mawera G, Asala SA, et al. Position of the mental foramen in adult black Zimbabwean mandibles: A clinical anatomical study. Cent Afr J Med. 1998;44(2):24-30.

7. Gershenson A, Nathan H, Luchansky E. Mental foramen and mental nerve: Changes with age. Acta Anat (Basel). 1986;126(1):21-28.

8. Moiseiwitsch JR. Position of the mental foramen in a North American, white population. Oral Surg Oral Med Oral Pathol Oral Radiol Endod. 1998;85(4):457-460.

9. Hoque MM, Ara S, Begum S, Mostafa Kamal AHM, Momen A (2013) Study of number, shape, size and position of mental foramen in Bangladeshi dry adult human mandible. Bangladesh Journal of Anatomy. 2013;11(1):7-10

10. Igbigbi PS, Lebona S. The position and dimensions of the mental foramen in adult Malawian mandibles. West Afr J Med. 2005;24(3):184-189.

11. Padilla JC, Cahuana EQ. Morphological and morphometric study of the mental foramen using cone-beam $\mathrm{CT}$ in dentate adult patients. Odontoestomatología. 2014;6(24): 4-12.

12. Budhiraja V, Rastogi R, Lalwani R, et al. Study of position, shape, and size of mental foramen utilizing Various parameters in dry adult human mandibles from north India. ISRN Anat. 2012;2013: 961429.

13. Mwaniki DL, Hassanali J. The position of mandibular and mental foramina in Kenyan African mandibles. East Afr Med J. 1992;69(4):210-213.

14. Al Jasser NM, Nwoku AL. Radiographic study of the mental foramen in a selected Saudi population. Dentomaxillofac Radiol. 1998;27(6): 341-343.

15. Sawyer DR, Kiely ML, Pyle MA. The frequency of accessory mental foramina in four ethnic groups. Arch Oral Biol. 1998;43(5): 417-420.

16. Defreitas V, Madeira MC, Tsledofilhs JL, et al. Absence of the mental foramen in dry human mandible. Acta Anat. 1979;104(3):353-355.

17. Singh R, Srivastav AK. Study of position, shape, size and incidence of mental foramen and accessory mental foramen in Indian adult human skull. Int J Morphol. 2010;28(4):1141-1146.

18. Ulu M, Tarim Ertas E, Gunhan F, et al. Unilateral absence of mental foramen with surgical exploration in a living human subjects. Case Rep Dent. 2016;2016:1971925.

19. Lauhr G, Coutant JC, Normand E, et al. Bilateral absence of mental foramen in a living human subject. Surg Radiol Anat. 2015;37(4):403-405.

20. Agarwal DR, Gupta SB. Morphometric analysis of mental foramen in human mandibles of south Gujarat. People's Journal of Scientific Research. 2011;4(1):15-18.

21. Oguz O, Bozkir MG. Evaluation of location of mandibular and mental foramina in dry, young, adult human male, dentulous mandibles. West Indian Med J. 2002;51(1):14-16.

22. Ilayperuma I, Nanayakkara G, Palahepitiya N . Morphometric analysis of the mental foramen in adult Sri Lankan mandibles. Int $J$ Morphol. 2009;27(4):1019-1024

23. Cutright B, Quillopa N, Schubert W. An Anthropometric Analysis of the Key Foramina for Maxillofacial Surgery. J Oral Maxillofac Surg. 2003;61(3):354-357.

24. Amorim MM, Prado FB, Borini CB, et al. The mental foramen in dentate and edentulous Brazilian's mandible. Int J Morphol. 2008;26(4):981-987. 
25. Green RM. The position of mental foramen: a comparison between the southern (Hong Kong) Chinese and other ethnic and racial group. Oral Surg Oral Med Oral Pathol. 1987;63(3):287-290.

26. Agthong S, Huanmanop T, Chentanez V. Anatomical variations of the supraorbital, infraorbital and mental foramina related to gender and side. J Oral Maxillofac Surg. 2005;63(6):800-804.
27. Phillips JL, Weller RN, Kulild JC. The mental foramen: 1. Size, orientation and positional relationship to the mandibular second premolar. $J$ Endod. $1990 ; 16(5): 221-223$. 